\title{
The impacts of Lachancea thermotolerans yeast strains on winemaking
}

\author{
Santiago Benito
}

\begin{abstract}
At one time, Saccharomyces spp. yeasts were the only option for use in winemaking due to their unique abilities to metabolize all grape juice sugars to ethanol. However, during the previous decade, several commercial nonSaccharomyces yeast products appeared in the biotechnology market. Some of them have slowly begun to establish new enological resources to solve modern winemaking challenges in the new century. Among these challenges, acidification in the warm-growing regions is of great concern for improving wine quality from those areas, particularly in light of the predictions of serious climate change. This review explores one of the most popular commercialized nonSaccharomyces yeast options in warm viticultural regions, Lachancea thermotolerans, and its influences on wine quality parameters, such as lactic acid, ethanol, glycerol, volatile acidity, volatile profiles, isovaleric acid, mannoproteins, polysaccharides, color, anthocyanins, amino acids, and sensory perception.
\end{abstract}

\section{Introduction}

Modern winemaking has begun to focus on nonSaccharomyces yeast species to generate methods to solve the current challenges in contemporary enology (Jolly et al. 2014; Padilla et al. 2016; Varela 2016; Petruzzi et al. 2017; Benito et al. 2018a). Typically, these non-Saccharomyces yeasts would lead the first steps of spontaneous fermentations before the addition of commercially available active dried Saccharomyces yeast products. However, today, there are commercially available active dried non-Saccharomyces yeast products that allow for the simulation of natural spontaneous fermentations during controlled conditions. These modern products, available from the primary manufacturers of active dried yeasts, include Torulaspora delbrueckii (Benito et al. 2018a), Schizosaccharomyces pombe (Benito et al. 2016a), Metschnikowia pulcherrima (Varela et al. 2016b), and Pichia kluyveri (Benito et al. 2015a). Other non-Saccharomyces yeasts that have shown interesting properties are not yet available in the general active dried yeast market. These species include Candida zemplinina, Kloeckera apiculata, Hanseniaspora vineae, Hanseniaspora uvarum, C. stellata (Jolly et al. 2003a), Kazachstania aerobia (Whitener et al. 2017), and Schizosaccharomyces japonicus (Domizio et al. 2017). Among the non-Saccharomyces yeasts, Lachancea thermotolerans is currently the yeast most frequently used at the industrial level to acidify low-acidic grape juices from warm viticultural regions to attain higher quality wines (Benito et al. 2016b). Tables 1 and 2 summarize the main applications for non-Saccharomyces species in winemaking.

In winemaking, non-Saccharomyces yeast applications are studied to improve several wine quality factors, such as acidity (Balikci et al. 2016), aromatic complexity (Belda et al. 2017), glycerol content (Belda et al. 2015), ethanol reduction (Contreras et al. 2014), mannoproteins (Belda et al. 2015), anthocyanins (Benito et al. 2017), and polysaccharide concentrations (Domizio et al. 2014; Domizio et al. 2017). They can also decrease the concentrations of unwanted compounds that affect food safety, such as ochratoxin A (Ponsone et al. 2011; Ponsone et al. 2016), ethyl carbamate, and biogenic amines (Benito et al. 2015b). However, using non-Saccharomyces yeasts on a large scale in a winery is complex, and their management differs greatly from that of the classic Saccharomyces yeasts. The key difficulty on the industrial fermentation scale is that most non-Saccharomyces yeasts possess low to 
Table 1 Primary advantages of using non-Saccharomyces species for winemaking applications

\begin{tabular}{ll}
\hline Yeast species & Advantages \\
\hline Torulospora delbrueckii & Acetic acid $\downarrow$, aroma complexity $\uparrow$, thiols $\uparrow$ \\
Metschnikowia pulcherrima & Esters $\uparrow$, terpenes $\uparrow$, thiols $\uparrow$, aroma complexity $\uparrow$ \\
Kloeckera apiculata & Aroma complexity $\uparrow$ \\
Hanseniaspora vineae & Aroma complexity $\uparrow, 2$-phenyl-ethyl acetate $\uparrow$, biogenic amines $\downarrow$ \\
Hansenula anomala & Decrease of $\mathrm{C} 6$ alcohols \\
Pichia kluvveri & Aroma complexity $\uparrow$, thiols $\uparrow$, esters $\uparrow$ \\
Pichia guillermondii & Color stability $\uparrow$ \\
Candida stellata & Glycerol $\uparrow$ \\
Zygosaccharomyces bailii & Polysaccharides $\uparrow$ \\
Schizosaccharomyces pombe & L-malic acid $\downarrow$, deacidification $\uparrow$ \\
Lachancea thermotolerans & L-lactic acid $\uparrow$, acidification $\uparrow$ \\
\hline
\end{tabular}

moderate alcoholic fermentation abilities and, therefore, the production of regular wines is not possible for most nonSaccharomyces yeasts when they function alone in pure cultures. However, the results using non-Saccharomyces yeasts in low-alcohol industries (below $10 \% v / v$ ), such as beer or the base for sparkling wine, appear to be promising for moderate fermentative species, such as $L$. thermotolerans (Domizio et al. 2016) or T. delbrueckii (González-Royo et al. 2015; Canonico et al. 2016; Michel et al. 2016; Canonico et al. 2017; Zamora; Benito et al. 2018a). Therefore, most studies using non-Saccharomyces yeasts for fermentation in winemaking combine those yeasts with one that ferments more strongly, such as Saccharomyces (Belda et al. 2017) or Schizosaccharomyces (Benito et al. 2017).

Global climate change is causing a shift in the grapes used for winemaking, leading to increasing sugar content and serious decreases in the acidities of grape juices, particularly those that originate in warm and temperate climates. Some viticultural regions that traditionally have been considered cool climates are beginning to suffer from similar concerns. The most common solution to manage a lack of acidity is the addition of commercial food-quality acids, such as tartaric acid, lactic acid, or citric acid. However, the use of industrial acids presents other problems, primarily a lack of chemical stability.

Table 2 Summary of the enological influences on wine quality for the primary commercial non-Saccharomyces strains available on the active dry yeast market

\begin{tabular}{|c|c|c|c|}
\hline Product name & Manufacturer & Species & Winemaking applications \\
\hline Prelude TM & $\begin{array}{l}\text { Chr. Hansen } \\
\text { www.chr-hansen.com }\end{array}$ & T. delbrueckii & $\begin{array}{l}\text { Volatile acidity } \downarrow \text {, medium-chain fatty-acid esters } \uparrow \text {, } \\
\text { flavor complexity } \uparrow \text {, toxic medium-chain fatty } \\
\text { acids } \downarrow \text {, mannoproteins } \uparrow\end{array}$ \\
\hline Zymaflore® Alpha & $\begin{array}{l}\text { Laffort } \\
\text { www.laffort.com }\end{array}$ & T. delbrueckii & $\begin{array}{l}\text { Volatile acidity } \downarrow, \mathrm{POF}(-) \text {, acetaldehyde } \downarrow \text {, acetoin } \downarrow \text {, } \\
\text { diacetyl } \downarrow \text { and } \mathrm{H}_{2} \mathrm{~S} \downarrow, 3 \mathrm{SH} \uparrow, 3 \mathrm{SHA} \uparrow \text {, aromatic } \\
\text { diversity and intensity } \uparrow\end{array}$ \\
\hline Biodiva $^{\mathrm{TM}}$ & $\begin{array}{l}\text { Lallemand } \\
\text { www.lallemandwine.com }\end{array}$ & T. delbrueckii & $\begin{array}{l}\text { Aromatic esters } \uparrow \text {, volatile acidity } \downarrow \text {, osmotic shock } \\
\text { resistance } \uparrow \text { aromatic/mouthfeel complexity } \uparrow\end{array}$ \\
\hline Flavia® & $\begin{array}{l}\text { Lallemand } \\
\text { www.lallemandwine.com }\end{array}$ & M. pulcherrima & Aroma complexity $\uparrow$, thiols $\uparrow$, esters $\uparrow$ \\
\hline Viniferm NS TD & $\begin{array}{l}\text { Agrovin } \\
\text { www.agrovin.com }\end{array}$ & T. delbrueckii & $\begin{array}{c}\text { Aromatic spectrum } \uparrow \text {, B-phenyl ethanol } \uparrow, B \text {-lyase } \\
\text { activity } \uparrow \text {, mannoprotein } \uparrow \text {, wine complexity } \uparrow\end{array}$ \\
\hline Primaflora ${ }^{\circledR}$ VB BIO & $\begin{array}{l}\text { CENOLIA } \\
\text { www.sud-et-bio.com }\end{array}$ & T. delbrueckii & Bio-protection $\uparrow$ \\
\hline Frootzen $\circledast$ & $\begin{array}{l}\text { Chr. Hansen } \\
\text { www.chr-hansen.com }\end{array}$ & P. kluyveri & Aroma complexity $\uparrow$, thiols $\uparrow$, esters $\uparrow$ \\
\hline ProMalic & $\begin{array}{l}\text { Proenol } \\
\text { https://www.proenol.com }\end{array}$ & S. pombe & L-Malic acid $\downarrow$, deacidification $\uparrow$ \\
\hline Concerto $^{\mathrm{TM}}$ & $\begin{array}{l}\text { Chr. Hansen } \\
\text { www.chr-hansen.com }\end{array}$ & L. thermotolerans & $\begin{array}{l}\text { Lactic acid } \uparrow \text {, total acidity } \uparrow \text {, ethyl isobutyrate } \uparrow \text {, } \\
\text { aroma complexity } \uparrow\end{array}$ \\
\hline Melody ${ }^{\mathrm{TM}}$ & $\begin{array}{l}\text { Chr. Hansen } \\
\text { www.chr-hansen.com }\end{array}$ & $\begin{array}{l}\text { L. thermotolerans, } \\
\text { T. delbrueckii, S, cerevisiae }\end{array}$ & $\begin{array}{l}\text { Tropical fruitiness } \uparrow \text {, aromatic intensity } \uparrow \text {, } \\
\text { balanced mouthfeel } \uparrow\end{array}$ \\
\hline
\end{tabular}


Tartaric acid precipitates when it binds to potassium, reducing the total acidity of wine, while lactic acid bacteria easily metabolize citric acid, producing undesirable acetic acid. When the required acidity corrections are needed, the use of expensive food-quality acids can increase the final costs of wine production. With this in mind, microbiological acidification using $L$. thermotolerans provides an important winemaking resource, allowing the production of quality wines in warm climate viticultural regions due to its ability to increase wine acidity and other secondary parameters.

One of the classic uses of $L$. thermotolerans in winemaking has been to improve acidity (Benito et al. 2016b). Recently, however, its ability to improve other wine quality parameters, such as ochratoxin A (Ponsone et al. 2011; Ponsone et al. 2016), biogenic amines (Benito et al. 2015b), ethyl carbamate (Benito et al. 2016c), aroma complexity (Comitini et al. 2011), ethanol reduction (Ciani et al. 2006; Ciani et al. 2016), and glycerol (Kapsopoulou et al. 2007; Shekhawat et al. 2018), or even for beer production (Domizio et al. 2016), has led to an increase in the use of this enological resource. Recent studies have shown that some of these properties are highly straindependent (Comitini et al. 2011; Du Plessis et al. 2017; Escribano et al. 2018). In contrast, some studies have begun to isolate large numbers of genetically different $L$. thermotelarans strains from various ecosystems that could also result in different fermentation phenotypes (Hranilovic et al. 2017a). Therefore, strain selection, evaluation, and screening must be performed for $L$. thermotolerans species, as was done for $S$. cerevisiae in the past, or, more recently, for other nonSaccharomyces yeasts, such as Schizosaccharomyces (Benito et al. 2016a). Specific criteria must be chosen to increase the primary virtues of an $L$. thermotolerans species, while decreasing its weaknesses. These selection processes will increase the number of commercially available strains, allowing for better adaptation to specific scenarios. Currently, only two commercial products that include $L$. thermotolerans yeast species in their composition are available on the market. One option named CONCERTO ${ }^{\mathrm{TM}}$ includes only $L$. thermotolerans, while the other option named MELODY ${ }^{\mathrm{TM}}$ offers the yeast combined with $T$. delbrueckii and $S$. cerevisiae (http://www.chr-hansen. com). During the next few years, however, manufacturers will likely increase the available options, comparable to the situation in recent years for the most commercialized nonSaccharomyces $T$. delbrueckii; this yeast currently has five commercial strains on the market (Benito et al. 2018a). Table 2 summarizes the primary commercial dried yeast options available on the market and their possible applications according to their manufacturers.

The manufacturer of CONCERTO ${ }^{\mathrm{TM}}$ (http://www.chrhansen.com) offers the $L$. thermotolerans dried yeast as a natural microbial solution to increase the total acidity of wine (Table 2). It is recommended that this yeast be used to partially ferment grape juices produced in warm climates, since it produces lactic acid, giving roundness and balanced acidity to the wines, and therefore, improving their freshness. In addition to acidic freshness, this yeast enhances the flavor complexity. CONCERTO ${ }^{\mathrm{TM}}$ also produces ethyl isobutyrate, a primary component of fresh strawberry aroma, which increases the fiuity character of the wine. The manufacturer recommends inoculating $S$. cerevisiae into red, rose, or white wines from warm to hot viticultural areas after 2-3 days of fermentation with $L$. thermotolerans to ensure a proper conclusion of the alcoholic fermentation (http://www.chr-hansen.com).

Studies of $L$. thermotolerans have increased considerably during the last few years, similar to the situation with $S$. cerevisiae research in the early days of wine microbiology or, more recently, for non-Saccharomyces yeasts, such as $T$. delbrueckii (Benito et al. 2018a) or $S$. pombe (Benito et al. 2018b). This study aims to review the most recent scientific data on L. thermotolerans, while analyzing the contradictions that have been seen in some cases. This review will help enologists to better understand the potential industrial uses of modern scenarios, allowing them to make the proper decisions regarding the use of $L$. thermotolerans, while avoiding possible management mistakes.

\section{Taxonomy, morphology, and physiology of $L$. thermotolerans}

\section{Lachancea spp.}

Lachance and Kurtzman (2011) renamed several genera assigned to the Saccharomycetaceae. In the past, phenotypic studies had been primarily used to define these groups, but later classifications grouped them by phylogenetic analysis of their gene sequences. A multigene sequence analysis (Kurtzman and Robnett 2003) resolved the family Saccharomycetaceae into 11 well-supported clades. The last taxonomic organization of the Saccharomycetaceae was evaluated according to this multigene sequence analysis, resulting in the reassignment of some species among the currently accepted genera and the proposal of five new genera: Lachancea, Nakaseomyces, Naumovia, Vanderwaltozyma, and Zygotorulaspora. Since then, former Kluyveromyces spp., such as $K$. thermotholerans, are now known as $L$. thermotolerans (Lachance and Kurtzman 2011). However, some current commercial products still use the former genera classification in their descriptions.

Lachance and Kurtzman (2011) recognized six species belonging to the Lachancea genus: L. cidri (Legakis) Kurtzman (2003), L. fermentati (H. Naganishi) Kurtzman (2003), L. kluyveri (Phaff, M.W. Miller \& Shifrine) Kurtzman (2003), L. meyersii Fell et al. (2004), L. thermotolerans (Filippov) Kurtzman (2003), and L. waltii (K. Kodama) Kurtzman (2003). The considered type species is $L$. thermotolerans. The corresponding classification criteria 
comprise the positive or negative capacity to grow in media containing $0.01 \%$ cycloheximide, culture growth at $37{ }^{\circ} \mathrm{C}$, and the ability to assimilate melibiose, melezitose, and Lsorbose (Lachance and Kurtzman 2011).

The genus reproduces asexually by multilateral budding. On some occasions, pseudohyphae are formed, but true hyphae are never formed. Sexual reproduction takes place through ascus formation, containing one to four spherical ascospores. With respect to physiology and biochemistry, Lachancea ferments glucose intensively, and it does not assimilate nitrate. Ethylamine can be used as the sole nitrogen source. Coenzyme Q-6 is the primary ubiquinone, and the diazonium blue B test is negative. These properties appear to be the key points in the optimization of specific Lachancea selective media, based on antibiotics (e.g., cycloheximide) and carbon sources (e.g., melezitose) that inhibit the development of possible competitor yeasts, ethylamine as a unique nitrogen source, and incubation specifically at $37{ }^{\circ} \mathrm{C}$. The Lachancea genus appears among the 20 most frequently described foodborne yeasts (Fig. 1). The reported presence among other yeasts in nature varies from $2 \%$ in fruits, beverages, wine, and beer to $5 \%$ in low-water-activity $\left(a_{\mathrm{w}}\right.$; i.e., dry) products (Deák 2008). This species is occasionally isolated

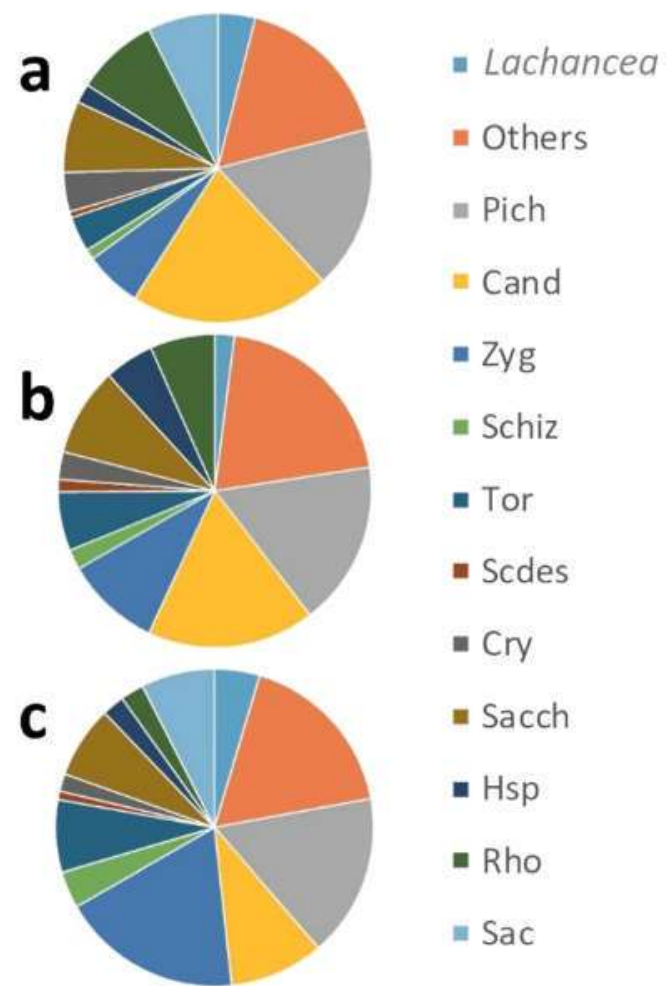

Fig. 1 Simplified model of the frequencies (\%) of yeast genera found in foods established by Deák (2008). a All foods; b fruits, beverages, wine, and beer; $\mathbf{c}$ low- $a_{\mathrm{w}}$ products. The incidence of the genus Lachancea is shown with respect to the other most frequent genera. Sacch, Saccharomyces; Zygo, Zygosaccharomyces; Sch, Schizosaccharomyces; Sdes, Saccharomycodes; Sac, Saccharomyces; Rho, Rhodotorula; Tor, Torulaspora; Hsp, Hanseniaspora; Dek, Dekkera; Cry, Cryptococcus from fermented foods (Senses-Ergul et al. 2006), in addition to cocoa fermentation (Schwan and Wheals 2003). It is commonly found in fruit and in various Drosophila species (Lachance and Kurtzman 2011).

The isolation criteria provided in the genus description could allow for the optimization of selective differential media, similar to those optimized in the past for other nonSaccharomyces, such as Brettanomyces/Dekkera or Schizosaccharomyces (Benito et al. 2018b). The primary selective factors for the selective isolation of the Lachancea genus could include antibiotics, such as cycloheximide; high culture temperature incubations of approximately $37^{\circ} \mathrm{C}$; selective carbon sources, such as melezitose, and differential factors, such as diazonium blue B stain. These selective differential factors allow for the easy initial isolation of representative strains before proceeding to the selection processes that have been used in the past to screen other non-Saccharomyces (Benito et al. 2016a) yeasts. The lack of a specific selective media and the relatively low incidence in nature compared to other yeast species may explain why there is only one commercial strain currently available on the market.

\section{L. thermotolerans}

L. thermotolerans is the type species from the Lachancea genus, and it is the most common species from this genus that is currently used in winemaking. The species has also previously been designated Zygosaccharomyces thermotolerans, $S$. thermotolerans, K. thermotolerans, Zygofabospora thermotolerans, Torula dattila Kluyver, Mycotorula dattila, Torulopsis dattila, Cryptococcus dattilus, Candida dattila, S. veronae, $K$. veronae, and Zygosaccharomyces drosophilae (Lachance and Kurtzman 2011). The most popular available commercial product based on $L$. thermotolerans remains marketed under its former name, Kluyveromyces thermotolerans (https://www.chr-hansen.com/en/foodcultures-and-enzymes/wine/cards/product-cards/concerto? countryreset $=1$ ).

L. thermotolerans species are able to grow in some testing media used to classify yeast genera, such as xylitol, amino acid-free, ethylamine, lysine, or $50 \%$ glucose media (Lachance and Kurtzman 2011). L. thermotolerans species have spherical to ellipsoidal cells that are slightly smaller than those of $S$. cerevisiae, with dimensions of approximately $3-$ $6 \times 6-8 \mu \mathrm{m}$ (Fig. 2).

Banilas et al. (2016) introduced a method based on multilocus SSR analysis for the molecular typing and detection of genetic diversity among $L$. thermotolerans isolates. This technique allows researchers to easily identify yeasts at the species level, and after following a whole genome screening, five polymorphic microsatellite markers provide the ability to discriminate among the different strains. The identification of the different strains indicate the tremendous genotype 


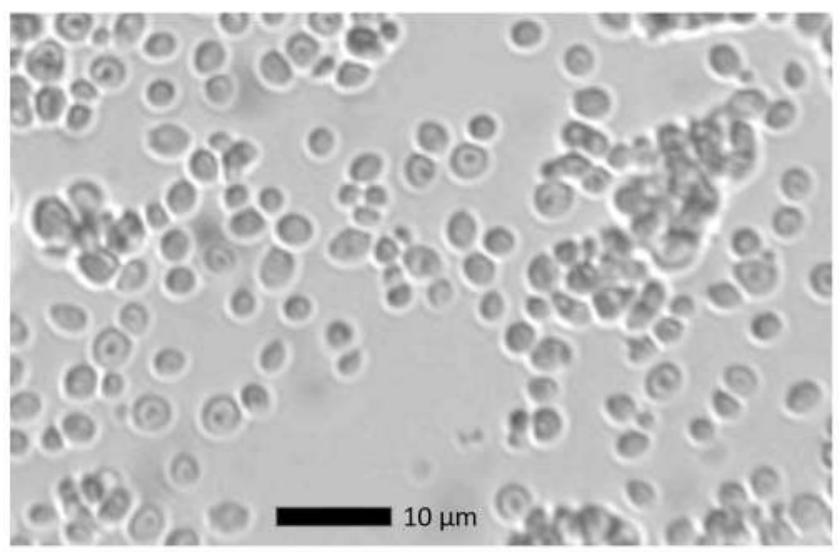

Fig. 2 Microscopic observation of Lachancea thermotolerans cells. Source: the author's data

diversity that later will explain the high strain variability in certain fermentation parameters.

Some authors have reported that $L$. thermotolerans (Malpertuy et al. 2000) genes have a high degree of sequence homology with those of $S$. pombe. This fact is of great interest for producing hybrids between the two species that will easily solve modern enological problems related to warm viticultural regions, such as malolactic fermentation performance in high$\mathrm{pH}$ grape juices. Some of the current problems related to food safety parameters and acidity are solved through the management of sequential fermentations using both $L$. thermotolerans and S. pombe (Benito et al. 2015b).

\section{Clonal diversity within L. thermotolerans species}

Recently, studies have reported that there is significant variability among important enology parameters at the clonal level when the fermentations among several different $L$. thermotolerans strains are compared. Escribano et al. (2018) reported statistically significant differences in lactic acid production of approximately $3.3 \mathrm{~g} / \mathrm{L}$. The lactic acid produced led to variations in the $\mathrm{pH}$ and the total acidity of approximately 0.2 and $2.3 \mathrm{~g} / \mathrm{L}$, depending on the different strains being studied. Volatile acidity showed a variability of approximately $0.14 \mathrm{~g} / \mathrm{L}$. The same study reported differences in pyruvic acid and succinic acid synthesis of approximately 8.5 and $151 \mathrm{mg} /$ $\mathrm{L}$, respectively. Volatile higher alcohols, such as 1-propanol and isobutanol, showed variability up to 63 and $34 \%$, respectively, depending on the clone of interest. Esters, such as ethyl acetate and ethyl lactate, showed variability up to 22.5 and $76.3 \%$, respectively, depending on the clone of interest. Variations in isovaleric acid were approximately $50 \%$. The greatest variability was identified for acetoin, with final concentrations varying from 4.6 to $108 \mu \mathrm{g} / \mathrm{L}$. These results indicate the importance of proper clonal selection when searching for the most appropriate $L$. thermotolerans strains for the wine industry, ultimately leading to an enhancement in characteristics such as lactic acid production, while minimizing volatile acidity, succinic acid, isovaleric acid, or acetoin production. Table 3 summarizes the results of these studies, comparing the fermentation performance of several $L$. thermotolerans strains.

\section{Impact of $L$. thermotolerans on different wine fermentation parameters}

\section{L-lactic acid, titratable acidity, and pH}

Although lactic acid production is the most remarkable application of $L$. thermotolerans for winemaking, different researchers report great differences in its production varying from 0.3 to $9.6 \mathrm{~g} / \mathrm{L}$, depending on the strain being studied or the experimental conditions. Kapsopoulou et al. (2005) reported that one strain of $L$. thermotolerans in pure fermentation produced $9.6 \mathrm{~g} / \mathrm{L}$ of lactic acid, while the $S$. cerevisiae control did not show any increase in its final L-lactic acid concentration. That concentration of lactic acid increased the final titratable acidity to $9.4 \mathrm{~g} / \mathrm{L}$ higher than that of $S$. cerevisiae, reducing the final $\mathrm{pH}$ from 3.15 to 2.9 . However, $L$. thermotolerans did not properly complete the alcoholic fermentation, leaving $38 \mathrm{~g} / \mathrm{L}$ of residual sugar, while the $S$. cerevisiae control completed the alcoholic fermentation process with only $1.6 \mathrm{~g} / \mathrm{L}$ of residual sugar remaining. In most cases, later studies have reported fewer differences in lactic acid production when $L$. thermotolerans is used in combined fermentations with stronger fermenters, such as $S$. cerevisiae or $S$. pombe, instead of pure culture fermentations to ensure a proper complete alcoholic fermentation. The same author (Kapsopoulou et al. 2007) later reported smaller increases in total acidity varying from 0.6 to $5 \mathrm{~g} / \mathrm{L}$, depending on the mixed culture modality used in combination with $S$. cerevisiae. The lactic acid production varied from 0.18 to $5.13 \mathrm{~g} / \mathrm{L}$, and the final $\mathrm{pH}$ values varied from 3.2 to 3.43 . Although other studies did not specifically investigate the final lactic acid concentrations (Comitini et al. 2011), they did report significant increases in the total acidity that varied from 0.3 to $2.2 \mathrm{~g} / \mathrm{L}$, depending on the proportion of $S$. cerevisiae to $L$. thermotolerans in the initial inocula. This led to decreases in the $\mathrm{pH}$ of up to 0.3 units. Gobbi et al. (2013) observed more moderate increases in the final lactic acid concentrations, with $3.43 \mathrm{~g} / \mathrm{L}$ for a pure fermentation by $L$. thermotolerans, $1.55 \mathrm{~g} / \mathrm{L}$ for a sequential fermentation with $S$. cerevisiae, and $0.81 \mathrm{~g} / \mathrm{L}$ for a co-culture. The variations in total acidity varied from 7.26 to $9.53 \mathrm{~g} / \mathrm{L}$, while the $\mathrm{pH}$ varied from 3.33 to 3.53 . The influence of this metabolism is very useful to increase the acidity of low-acidity white grape juices from warm viticultural areas (Benito et al. 2016b), such as the Airen grape variety in the south of Spain, since it clearly affects the final quality 
Table 3 Summary of the variability among $L$. thermotolerans strains for reported phenotypic responses to physiochemical fermentation parameters

\begin{tabular}{|c|c|c|c|}
\hline Parameter & Comitini et al. 2011 & Du Plessis et al. 2017 & Escribano et al. 2018 \\
\hline $\mathrm{SO}_{2}$ resistance $(\%)$ & $33 \%$ & & \\
\hline Glucosidase activity & \pm & & \\
\hline Esterase activity & $0 / 1$ & & \\
\hline $\mathrm{H}_{2} \mathrm{~S}$ production $(\%)$ & $40 \%$ & & \\
\hline Fermentation power $(\% v / v)$ & $3.98-7.96$ & $9.31-10.35$ & \\
\hline Volatile acidity $(\mathrm{g} / \mathrm{L})$ & $0.32-0.58$ & $0.1-0.18$ & $0.14-0.28$ \\
\hline Polysaccharides (mg/L) & $163-260$ & & \\
\hline Malic acid degradation (\%) & & $10-20$ & \\
\hline Lactic acid production $(\mathrm{g} / \mathrm{L})$ & & & $0.9-4.2$ \\
\hline Pyruvic acid (mg/L) & & & $20-28.5$ \\
\hline Succinic acid (mg/L) & & & $287-438$ \\
\hline 1-Propanol (mg/L) & & & $20.5-55.4$ \\
\hline Isobutanol (mg/L) & & & $20.6-31.1$ \\
\hline Methionol (mg/L) & & & $0.67-2.6$ \\
\hline Ethyl acetate $(\mathrm{mg} / \mathrm{L})$ & & & $31-51$ \\
\hline Ethyl lactate (mg/L) & & & $5.5-23.2$ \\
\hline Acetoin $(\mathrm{mg} / \mathrm{L})$ & & & $4.6-108$ \\
\hline Isovaleric acid (mg/L) & & & $0.9-2$ \\
\hline
\end{tabular}

of the wine. In the production of red wines from warm viticultural areas, the production of lactic acid by $L$. thermotolerans is much higher than the production incurred by typical lactic acid bacteria during malolactic fermentation (Benito et al. 2015b).

\section{Malic acid}

Although all studies report $L$. thermotolerans to be a high lactic acid producer during alcoholic fermentation, most studies also report that $L$. thermotolerans can degrade small amounts of L-malic acid. These degradations vary from $8 \%$ (Gobbi et al. 2013) to approximately $26 \%$ (Kapsopoulou et al. 2005). while some studies did not observe this phenomenon at all (Benito et al. 2015b: Escribano et al. 2018). That variability can be explained by the observations of the same phenomenon in other species, such as $S$. cerevisiae, that can degrade malic acid up to approximately $40 \%$. depending on the strain being studied (Bonciani et al. 2016). (Du Plessis et al.. 2017) reported variability for malic acid degradation between strains of approximately $50 \%$. However, in all cases, an increase in the total acidity and a decrease in the final $\mathrm{pH}$ occurred because there was a much stronger influence from the lactic acid formation than from the small amounts of malic acid degradation. Hranilovic et al. (2017b) observed a malic acid reduction of approximately $50 \%$ in an early harvest with higher malic acid concentration than in a later harvest with lower malic acid content where the effect did not occur for the Shiraz grape variety.

\section{Acetic acid}

Several studies have reported low acetic acid concentrations in wine when $L$. thermotolerans is involved. Kapsopoulou et al. (2005) observed differences of up to $0.23 \mathrm{~g} / \mathrm{L}$ in volatile acidity when pure cultures of $L$. thermotolerans and $S$. cerevisiae were compared. Comitini et al. (2011) observed a similar effect for five $L$. thermotolerans strains and three $S$. cerevisiae strains, in which the Saccharomyces strains produced approximately $50 \%$ more volatile acidity. The production of acetic acid between the different $L$. thermotolerans strains varied from 0.32 to $0.58 \mathrm{~g} / \mathrm{L}$. Later studies reported a similar effect in sequential fermentations with statistically significant differences of approximately $0.25 \mathrm{~g} / \mathrm{L}$ (Gobbi et al. 2013). When comparing mixed and sequential inoculations, other authors observed smaller differences in the volatile acidities of approximately $0.06 \mathrm{~g} / \mathrm{L}$ (Kapsopoulou et al. 2007) and $0.04 \mathrm{~g} / \mathrm{L}$ (Benito et al. 2015b), respectively, and these were not statistically significant (Ciani et al. 2006; Benito et al. 2015a). The latest studies that compare several $L$. thermotolerans strains reported a significant degree of variability, approximately $50 \%$, in the volatile acidity $(0.14-$ $0.28 \mathrm{~g} / \mathrm{L}$ ) of the strains (Escribano et al. 2018). Although all the selected clones produced wines below the fault threshold of $0.8 \mathrm{~g} / \mathrm{L}$, these results clearly show that volatile acidity production must be considered in the strain selection process, since it is performed for $S$. cerevisiae, where, typically, acetic acid is the second-most important parameter after residual sugar consumption. 


\section{Ethanol}

The first study that examined the potential use of $L$. thermotolerans in alcoholic fermentation described this species as possessing a lower fermentation power than the $S$. cerevisiae control (Kapsopoulou et al. 2005). The strain that was used for this study produced $7.58 \%(v / v)$ ethanol from an initial sugar concentration of $163 \mathrm{~g} / \mathrm{L}$, leaving $38.8 \mathrm{~g} / \mathrm{L}$ of residual sugars unfermented, while the $S$. cerevisiae control produced $9.6 \%(v / v)$ ethanol. It was because of these results that later studies combined $L$. thermotolerans with a more powerful fermenting species of yeast, such as $S$. cerevisiae (Ciani et al. 2006; Kapsopoulou et al. 2007) or S. pombe (Benito et al. 2015b). The purpose of that combination was to complete the alcoholic fermentation while increasing the acidity in a manner similar to that in real industry. The first studies on sequential fermentations using $L$. thermotolerans and $S$. cerevisiae reported lower levels of final ethanol concentrations $(0.3 \% v / v)$, depending on the time lag between the $L$. thermotolerans initial inoculation and the $S$. cerevisiae second inoculation. Comitini et al. (2011) described the fermentation power, an assay that determines the capacity to ferment certain sugars into ethanol, of $L$. thermotolerans as varying from 4.58 to $7.96 \%(\mathrm{v} / \mathrm{v})$ for the five strains studied, while that of three $S$. cerevisiae controls varied from 10.78 to $12.62 \%(v / v)$. Differences in the final ethanol production did not occur in mixed fermentations, although on this occasion, the fermentations were combined and not sequential. Some authors have described $L$. thermotolerans as being able to ferment concentrations greater than $10 \%(v / v)$ ethanol up to $10.35 \%(v / v)$ (Du Plessis et al., 2017) or 10.46\% $(v / v)$ (Gobbi et al. 2013). This fact indicates that selected $L$. thermotolerans strains could perform proper fermentation processes in lowalcohol beverages, such as beer (Domizio et al. 2016), sweet wines, or base sparkling wines without being combined with a more efficient fermenting yeast species. The same authors observed lower final ethanol levels for co-cultures and sequential fermentations, although some of the trials did not complete the fermentation process, with the residual sugars most likely remaining because the high nutrient consumption by $L$. thermotolerans before the $S$. cerevisiae inoculation left no nutrients for further activities. Later studies also described ethanol decreases of approximately $0.20 \%(\mathrm{v} / \mathrm{v})$ (Benito et al. 2015a) or $0.4 \%(v / v)$ (Hranilovic et al. 2017b).

\section{Glycerol}

Initial pure culture fermentations with $L$. thermotolerans showed lower levels of glycerol production than the $S$. cerevisiae control, resulting in up to $1.49 \mathrm{~g} / \mathrm{L}$ in an incomplete fermentation of sugars (Kapsopoulou et al. 2005). However, later studies of sequential inoculations between $L$. thermotolerans and $S$. cerevisiae revealed a relationship between the time of the $L$. thermotolerans performance and the increases in final glycerol concentrations of up to $0.93 \mathrm{~g} / \mathrm{L}$ (Kapsopoulou et al. 2007). These results indicate that, although $L$. thermotolerans is a less efficient fermenter, it possesses a greater capacity to produce glycerol. Although Comitini et al. (2011) did not observe differences in ethanol production in combined fermentations with varying initial inoculum proportions, differences in glycerol production did occur up to $1.12 \mathrm{~g} / \mathrm{L}$. These differences increased when there was a smaller proportion of $S$. cerevisiae in the initial inoculum. Gobbi et al. (2013) observed a similar effect, achieving increases in final glycerol concentration up to $0.69 \mathrm{~g} / \mathrm{L}$. The same authors observed that a co-culture using $L$. thermotolerans and $S$. cerevisiae produced $0.56 \mathrm{~g} / \mathrm{L}$ more glycerol when it fermented at $20^{\circ} \mathrm{C}$ than at $30{ }^{\circ} \mathrm{C}$. Later studies also described glycerol increases of approximately $0.29 \mathrm{~g} / \mathrm{L}$ in sequential fermentations (Benito et al. 2015a). Shekhawat et al. (2018) reported that increases in oxygenation led to increases in glycerol formation and reduced the ethanol yield from both pure cultures of $L$. thermotolerans and mixed fermentations with other yeasts.

\section{Fermentation kinetics}

Most studies have reported that sequential fermentations involving $L$. thermotolerans require more time to consume all the sugars. These periods can vary from 2 to 4 days (Benito et al. 2016c). Typically, no additional delay takes place during the initial mixed culture fermentations. The first study to examine $L$. thermotolerans in winemaking (Kapsopoulou et al. 2005) observed an exponential decrease of sugars for the $S$. cerevisiae control, while the less efficient fermentation by $L$. thermotolerans was more linear and took 20 more days, and the sugar consumption was still not complete. The cell growth in $L$. thermotolerans was similar to that in the $S$. cerevisiae control during the first days of fermentation, but a slow decrease in cell viability occurred for $L$. thermotolerans throughout the experiment until the last day of fermentation. The 20day delay and the presence of residual sugars led researchers to combine the efforts of $L$. thermotolerans and $S$. cerevisiae to accomplish the winemaking industry requirements to ferment dry wines in less time. The control of $L$. thermotolerans and $S$. cerevisiae cell growth during fermentation can be easily accomplished through the use of selective media, such as lysine agar, which restricts the development of the $S$. cerevisiae cells (Ciani et al. 2006; Benito et al. 2015a). Mixed and sequential fermentations between $L$. thermotolerans and $S$. cerevisiae indicated that, as soon as the $S$. cerevisiae cells are inoculated, the population of $L$. thermotolerans exponentially decreases; this phenomenon is directly related to the decreased production of lactic acid (Kapsopoulou et al. 2007). These results confirm that the finding that higher acidifications require a delay in the inoculation of $S$. cerevisiae, 
and additional studies on the compatibility of the strains of different yeast species are required. Benito et al. (Benito et al., $2015 \mathrm{a}, \mathrm{b})$ observed a slower decrease in $L$. thermotolerans viability when combined with $S$. pombe, resulting in greater lactic acid formation. Comitini et al. (2011) managed to maintain high numbers of viable $L$. thermotolerans cells, up to $10^{7} \mathrm{cfu} / \mathrm{mL}$, in mixed cultures with $S$. cerevisiae for $10-$ 15 days using variable inoculum ratios, rather than the conventional $1: 1$.

\section{Inhibition of spoilage fungi}

Another modern use for $L$. thermotolerans yeast is its application as an antifungal agent when sprayed on grapes, helping to improve the final quality of the wine. Biogenic amines, ethyl carbamate, and ochratoxin A (OTA) are the primary microbiological food safety concerns for wine, and the levels of these toxins often reach the legal limits set in some countries. The presence of OTA in wines results in a health risk to consumers, since it is classified as a possible carcinogen to humans (group 2B) by the International Agency for Research on Cancer (IARC, 1993). Based on the available scientific toxicological and exposure data, the European Union has established a maximum level of $2 \mu \mathrm{g} / \mathrm{kg}$ permitted for OTA in wines, musts, and grape juice, in addition to $10 \mu \mathrm{g} / \mathrm{kg}$ in raisins (European Commission, 2006).

Some strains of $L$. thermotolerans have been investigated to serve as efficient prevention control measures for OTA, because they can inhibit OTA accumulation by inhibiting the growth of ochratoxigenic fungi, both in vitro and in situ (Ponsone et al. 2011). This study reported that the $L$. thermotolerans yeast strains investigated could control the aggregate growth of Aspergillus carbonarius and A.niger, as well as the accumulation of OTA. The inhibitory effects were dependent on the ochratoxigenic species, the yeast strain being investigated, the $a_{\mathrm{w}}$ of the growth substrate, and the temperature. When the proposed biotechnology is used, OTA accumulation can be reduced from 3 to $100 \%$, and the growth rate of the spoilage fungi can be reduced from 11 to $82.5 \%$, depending on the conditions evaluated. Later studies demonstrated the efficiency of this new bio-pesticide technique on an industrial scale during both greenhouse and field conditions (Ponsone et al. 2016). This study showed that the $L$. thermotolerans strains investigated could control the accumulation of OTA by $A$. niger in wine grapes at the harvest stage. The inhibitory effects primarily depended on the ochratoxigenic species and the $L$. thermotolerans strains. In summary, the accumulation of OTA was reduced from 27 to $100 \%$, depending on the conditions evaluated.

Since there is a trend to reduce the use of chemical pesticides, the use of this biotechnology based on the yeast $L$. thermotolerans as a bio-pesticide appears to be very promising.

\section{Acetaldehyde}

The first study that examined $L$. thermotolerans and acetaldehyde production (Kapsopoulou et al. 2005) reported that one strain of $L$. thermotolerans in pure culture fermentation produced a higher final acetaldehyde concentration $(19 \mathrm{mg} / \mathrm{L})$ than the $S$. cerevisiae control. Most of the similar studies that followed reported either neutral or opposite results, although most of these experiments were performed in sequential fermentations with $S$. cerevisiae, where the specific influence of $L$. thermotolerans is often not easily evaluated. Ciani et al. (2006) reported that pure $L$. thermotolerans cultures produced $81 \mathrm{mg} / \mathrm{L}$ less acetaldehyde than the pure $S$. cerevisiae control, although more moderate decreases of approximately 36 and $63 \mathrm{mg} / \mathrm{L}$ were observed for mixed and sequential fermentations. Comitini et al. (2011) reported no differences in the final acetaldehyde concentrations between the co-cultures of $L$. thermotolerans and $S$. cerevisiae and the $S$. cerevisiae controls. Gobbi et al. (2013) observed no differences for pure culture fermentations, co-culture fermentations, or sequential fermentation after $24 \mathrm{~h}$; however, a slight increase of approximately $4 \mathrm{mg} / \mathrm{L}$ was observed in a sequential inoculation after $48 \mathrm{~h}$. In the same study, co-culture fermentations produced approximately $10 \mathrm{mg} / \mathrm{L}$ less acetaldehyde than the control at $20^{\circ} \mathrm{C}$, while this effect was not observed at all at $30^{\circ} \mathrm{C}$ (Gobbi et al. 2013). Later studies (Benito et al. 2015a) reported that sequential fermentations involving $L$. thermotolerans produced lower final acetaldehyde concentrations of approximately $15 \mathrm{mg} / \mathrm{L}$.

\section{Aroma compounds}

Studies have reported that $L$. thermotolerans produces fewer higher alcohols than S. cerevisiae (Gobbi et al. 2013; Benito et al. 2015a; Balikci et al. 2016; Escribano et al. 2018). Benito et al. (2015a) observed that sequential fermentations involving L. thermotolerans produced approximately $13 \%$ lower final concentrations of higher alcohols than the $S$. cerevisiae control. The greatest difference was observed for 3-methylbutanol at approximately $20 \mathrm{mg} / \mathrm{L}$. Other studies have reported similar results when a pure culture $L$. thermotolerans fermentation is compared with a $S$. cerevisiae control, resulting in a difference of approximately $49 \mathrm{mg} / \mathrm{L}$ in higher alcohols (Escribano et al. 2018). Another study reported that the greatest effects were seen in sequential fermentations for the primary higher alcohols, 2-methyl-1-propanol, 3-methyl-1butanol, and 2-methyl-1-butanol, with differences of up to 75,40 , and $20 \mathrm{mg} / \mathrm{L}$, respectively; however, the study did not observe the same effects for minor higher alcohols, such as 1-propanol or hexanol (Gobbi et al. 2013). Balikci et al. (2016) reported a similar effect for Emir wine, in which the final concentrations of the total higher alcohols were reduced from 55 to $35 \mathrm{mg} / \mathrm{L}$ in sequential fermentations involving $L$. 
thermotolerans, depending upon the timing of the second inoculation of $S$. cerevisiae. However, other studies have reported the opposite effect, with higher alcohol production of approximately $80-100 \mathrm{mg} / \mathrm{L}$ in mixed initial cultures of $L$. thermotolerans and S. cerevisiae (Comitini et al. 2011). Chen et al. (2018) reported an increase in 1-propanol of approximately $20 \mathrm{mg} / \mathrm{L}$, while 3-methyl-1-butanol and 2methyl-1-butanol decreased by 24 and $22 \mathrm{mg} / \mathrm{L}$, respectively. These results may be explained by the great strain variability (37\%) observed in the L. thermotolerans production of higher alcohols, such as 1-propanol or isobutanol (Escribano et al. 2018), or the influence of different oxygen conditions (Shekhawat et al. 2018).

Higher levels of 2-phenol ethanol were observed for one of the $L$. thermotolerans strains studied in a mixed culture fermentation, while the others showed no statistically significant differences compared to the $S$. cerevisiae control (Comitini et al. 2011). Similar effects were observed for a strain of $L$. thermotolerans used in sequential fermentations with increases varying from 10 to $25 \%$ (Gobbi et al. 2013). In the same study, the effect increased at $20^{\circ} \mathrm{C}$. Chen et al. (2018) observed a decrease of approximately $15 \mathrm{mg} / \mathrm{L}$ of 2-phenol ethanol, although no differences were observed for the corresponding ester 2-phenyl-acetate.

Benito et al. (2015a) reported an increase of approximately $30 \%$ in total ethyl esters; the primary differences were observed for ethyl lactate (33\%), ethyl butanoate (20\%), ethyl hexanoate $(10 \%)$, and ethyl decanoate $(10 \%)$. Hranilovic et al. (2017b) reported increases in the total acetate esters that varied from 29 to $33 \%$. In contrast, studies that compared pure culture $L$. thermotolerans and $S$. cerevisiae fermentations reported lower levels of acetate esters and ethyl esters, so we cannot conclude that the higher amount of ester formations was entirely due to L. thermotolerans (Escribano et al. 2018). Comitini et al. (2011) reported increases for mixed culture fermentations of approximately $3 \mathrm{mg} / \mathrm{L}$ of ethyl lactate, compared to the $S$. cerevisiae control, while no differences were observed in ethyl acetate and isoamyl acetate production. Other studies have reported increases in ethyl lactate of $14 \mathrm{mg} / \mathrm{L}$ (Benito et al. 2016b) and $\sim 32 \mathrm{mg} / \mathrm{L}$ (Chen et al. 2018 ) as a result of the greater lactic acid production in fermentations involving $L$. thermotolerans.

Lower fatty-acid concentrations have also been reported for these $L$. thermotolerans pure culture fermentations when compared to the $S$. cerevisiae control (Escribano et al. 2018). Studies have shown the lower production of hexanoic acid and octanoic acid by most $L$. thermotolerans strains in combined fermentations, while no effects have been observed for decanoic acid (Comitini et al. 2011). However, some strains of $L$. thermotolerans have been found to produce high levels of isovaleric acid (Escribano et al. 2018), which is considered a highly undesirable compound in wines due to its negative "cheesy" or "sweaty socks" sensory characteristic. Final concentrations of this compound varied from 0.95 to $2 \mathrm{mg}$ $\mathrm{L}$, depending on the strain studied. Other authors did not observe differences in fatty-acid formation during sequential fermentations involving $L$. thermotolerans and $S$. cerevisiae (Benito et al. 2015a).

An increase in the total terpenes of approximately $15 \%$ has also been noted for sequential inoculations of $L$. thermotolerans, in which both hotrienol and nerol showed specific increases of 10 and $47 \mu \mathrm{g} / \mathrm{L}$, respectively (Benito et al., 2015a, b). This effect could be closely related to the glusosidase activity reported for some $L$. thermotolerans strains (Comitini et al. 2011).

L. thermotolerans produced lower final concentrations of acetoin than the $S$. cerevisiae control $(11.9 \mathrm{mg} / \mathrm{L})$ in both pure $(3.4 \mathrm{mg} / \mathrm{L})$ and sequential inoculations $(2.2 \mathrm{mg} / \mathrm{L})$ in a study by Ciani et al. (2006), while other authors have observed no statistically significant differences (Chen et al. 2018). However, there is an exceptionally large amount of variability (nearly 100\%) in acetoin production, depending on the strain investigated (Escribano et al. 2018).

\section{Anthocyanins}

The first study regarding $L$. thermotolerans yeast and red wine reported a significant increase $(\sim 10 \%)$ in the color intensity in sequential fermentations with $S$. cerevisiae compared to the control of $S$. cerevisiae alone (Benito et al. 2015b). That phenomenon was attributed to the higher coloration of anthocyanin molecules at a lower $\mathrm{pH}$ and, in this specific case, was a consequence of increased lactic acid formation during the $L$. thermotolerans fermentation. Later studies observed an additional phenomenon related to decreased grape anthocyanin adsorption by $L$. thermotolerans (Benito et al. 2017) with increased higher final levels of anthocyanins from grapes (e.g., delphinidin-3-O-glucoside increase $25 \%$; cyanidin-3$\mathrm{O}$-glucoside increased $50 \%$; petunidin-3-O-glucoside increased 50\%; peonidin-3-O-glucoside increased $50 \%$, and malvidin-3-O-glucoside increased $4 \%$ ), when compared to $S$. cerevisiae fermentations alone. Another recent study reported similar results (Chen et al. 2018) and observed even greater increases. Hranilovic et al. (2017b) reported an increase of approximately $8 \%$ in the final anthocyanin concentrations after alcoholic fermentation involving $L$. thermotolerans compared to the $S$. cerevisiae control.

\section{Nitrogen metabolism}

Pure fermentations of $L$. thermotolerans do not produce higher final concentrations of assimilable nitrogen compounds than the pure $S$. cerevisiae control. However, mixed and sequential inoculations with $L$. thermotolerans and $S$. cerevisiae showed increases of approximately $25 \mathrm{mg} / \mathrm{L}$ (Ciani et al. 2006). Later studies observed that sequential alcoholic 
fermentations involving $L$. thermotolerans and $S$. cerevisiae produced higher final concentrations of lysine than the $S$. cerevisiae control (Benito et al., 2015a, b). Lysine is the precursor of the secondary biogenic amine, cadaverine. Other biogenic amine precursors, such as ornithine and tyrosine also slightly increased after fermentations involving $L$. thermotolerans (Benito et al. 2015a; Benito et al. 2016b). With "on the lees" aging of greater than 4 months, $L$. thermotolerans wines released higher concentrations of histidine, tyrosine, ornithine, and lysine than the $S$. cerevisiae controls, although no differences were observed in the final biogenic amine concentrations (Belda et al. 2016). There is no direct relationship between the precursor amino acids of the biogenic amines and the formation of biogenic amines as the result of microbial decarboxylation (e.g., from lactic acid bacteria). However, a selection of strains with low production/ release of these specific amino acids can help to reduce wine-related food safety concerns. Higher final levels of these amino acids (e.g., leucine and isoleucine) in sequential fermentations with $L$. thermotolerans are often related to a decrease in the production of higher alcohols, such as 3methylbutanol and 2-methylbutanol, compared to the $S$. cerevisiae controls (Benito et al. 2015a; Benito et al. 2016b). Escribano et al. (2018) observed higher final levels of assimilable nitrogen $(\sim 41 \mathrm{mg} / \mathrm{L})$ for pure culture fermentations that could be related to less demanding nitrogen needs, higher nitrogen release, or incomplete sugar fermentations.

\section{Polysaccharides and mannoproteins}

Specific species of non-Saccharomyces play a key role in current winemaking by increasing the concentrations of polysaccharides and mannoproteins in wines (Domizio et al. 2014, 2017). The presence of these compounds directly influence wine quality, particularly those parameters related to mouthfeel (Gonzalez-Ramos et al. 2008). However, a study of five $L$. thermotolerans strains reported variability of approximately $38 \%$ for polysaccharide concentrations following the fermentation process (Comitini et al. 2011). In the same study, the highest concentration of polysaccharides among the $L$. thermotolerans strains was $260 \mathrm{mg} / \mathrm{L}$, while the highest concentrations between the $S$. cerevisiae controls was $152 \mathrm{mg} / \mathrm{L}$. Gobbi et al. (2013) reported increases in polysaccharide concentrations varying from 30 to $60 \%$ in pure fermentations involving $L$. thermotolerans, in co-cultures, in $24-\mathrm{h}$ sequential inoculations, and in 48-h sequential inoculations, compared to the $S$. cerevisiae control. The effects were influenced by inoculation modality but not by temperature. Domizio et al. (2014) reported an increase of approximately $20 \%$ in the final polysaccharide concentrations compared to the $S$. cerevisiae control. Other studies have reported lower levels on the ethanol index, a parameter that estimates the combined amounts of polysaccharides and tannins, for one specific $L$. thermotolerans strain in sequential fermentations compared with the fermentations by $S$. cerevisiae pure controls (Benito et al. 2016b; Chen et al., 2018).

The use of $L$. thermotolerans in aging over lees has been reported as not producing higher final concentrations of mannoproteins than the $S$. cerevisiae control after 4 months; as expected, the $S$. cerevisiae control produced approximately $50 \%$ more mannoproteins expressed in mannose concentration (Belda et al. 2016).

\section{Sensory influence in wine}

Benito et al. (2015b) reported that $L$. thermotolerans sequential fermentations enhanced the perception of acidity. This perception was related to the increased levels of lactic acid (by $\sim 3 \mathrm{~g} / \mathrm{L}$ ) that decreased the $\mathrm{pH}$ by approximately 0.21 . Consequently, the overall impression of an initial grape juice with a low acidity significantly improved for the final wine when using $L$. thermotolerans for fermentations. The same study reported a higher perception of sweetness for the controls performed by $S$ cerevisiae, although all the wines contained similar levels of residual sugars. That effect appeared to be related to the different perceptions that depended on the balance between the acidity and the sweetness. In several studies, the perception of higher color intensity in the red wine fermented by $L$. thermotolerans (Benito et al. 2015b; Benito et al. 2016b; Benito et al. 2018a) can be explained by the low anthocyanin adsorption capacity of $L$. thermotolerans (Hranilovic et al., 2017a, b; Benito et al. 2018a), and the increase of red and purple colors at low $\mathrm{pH}$ values (Benito et al. 2016b). The decreased hue also appeared to be related to similar effects. Occasionally, decreased perceptions of oxidation were likely to be related to the lower levels of acetaldehydes, which often serve as an oxidation descriptor in wines. Reported increases in the overall impression from some grape varieties (e.g., Riesling) were most likely to be associated with the decreased production of higher alcohols that typically mask the varietal aromas, such as thiols, that provide a greater impact at the final perception (Benito et al. 2015a). Figure 3 summarizes the influences of $L$. thermotolerans on the sensory perception of fermented products.

\section{L. thermotolerans and S. pombe combined use}

L. thermotolerans is also able to compensate for the loss of acidity produced by other beneficial non-Saccharomyces yeasts such as Schizosaccharomyces during alcoholic fermentation. The use of Schizosaccharomyces in enology was focused on the deacidification of highly acidic grape juices from Northern European viticultural areas. In these circumstances, this yeast appeared to efficiently reduce the acidity through malic acid metabolism, in which malic acid is converted into ethanol (Benito et al., 2016a, b, c). In 


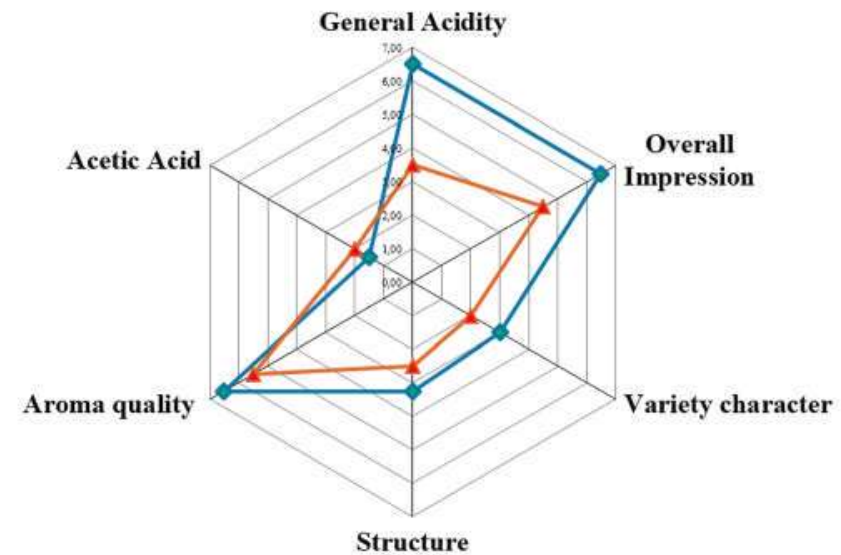

$\rightarrow$ Selected $L$. thermotolerans

$₫$ S. cerevisiae

Fig. 3 Summary of $L$. thermotolerans influences on the sensory perception of fermented products compared to typical fermentations by Saccharomyces cerevisiae. Source: the author's data

contrast, during recent years, Schizosaccharomyces has become more commonly used in warm viticultural regions, such as Southern Europe, to avoid some of the collateral negative effects produced during malolactic fermentation by lactic acid bacteria in the high-pH musts (Benito et al., 2016a, b, c; Domizio et al. 2017). Some of the effects produced during malolactic fermentation include the production of toxic or carcinogenic products, such as biogenic amines or ethyl carbamate; the loss of color and anthocyanins; an increase in acetic acid; the loss of fruity aromas, and an increase in wine production time (Mylona et al. 2016). However, the primary collateral effect of applying Schizosaccharomyces yeasts to grape juices from warm regions was the loss in acidity that affected its value in the international markets, despite the decreased health risks (Benito et al. 2015b). For that reason, L. thermotolerans is the perfect partner for $S$. pombe when fermenting grape juices with a lack of acidity (Benito et al. 2015b). In these circumstances, $L$. thermotolerans compensates for the loss of acidity produced by Schizosaccharomyces malic acid metabolism with the production of lactic acid and without a need for malolactic fermentation by lactic acid bacteria (Benito et al. 2015b). The production of lactic acid by $L$. thermotolerans is generally higher than that produced by Oenococcus oeni, reaching levels up to $\sim 2.21 \mathrm{~g} / \mathrm{L}$ more than the control using $S$. cerevisiae and $O$. oeni, because the final lactic acid concentration does not depend on the initial malic acid content (Benito et al. 2015b). Although combined fermentations with $L$. thermotolerans and $S$. pombe showed similar final levels of acetic acid compared to the control fermentation with $S$. cerevisiae, the concentration of acetic acid did increase up to $0.12 \mathrm{~g} / \mathrm{L}$, most likely due to the citric acid metabolism occurring by lactic acid bacteria during malolactic fermentation (Benito et al. 2015b). Later studies demonstrated that this new biotechnology that avoids malolactic fermentation in high-pH scenarios produces wines with up to fourfold lower histamine concentrations (Benito et al. 2016b). The same study showed the positive effects of increased acidity and increased fruity esters (yielding a fruity aroma) on improved sensory perception. Later studies showed that combined fermentation positively influences the color of red wine, not only because of low anthocyanin adsorption by $L$. thermotolerans but also because of the production of highly stable anthocyanin color forms, such as vitisins A and B, by $S$. pombe (Benito et al. 2017). In addition, the negative effects of lactic acid bacteria on the anthocyanin concentrations and final red color that usually reduce these factors by approximately 10 to $20 \%$ are not observed, because no malolactic fermentation is needed (Benito et al. 2017). The latest studies corroborate the improvements in vitisins of approximately $20 \%$ and the color intensity of approximately $22 \%$, even though no controls were performed for malolactic fermentation (Escott et al. 2018).

Although the combined use of $L$. thermotolerans and $S$. pombe has been reported to improve several wine quality parameters, fermentations involving sequential inoculations on an industrial scale are more difficult for winemakers to perform than regular fermentations using a unique species. For that reason, future research is focusing on genetic hybridizations between $L$. thermotolerans and $S$. pombe (unpublished; personal communication) to acquire a hybrid species that can perform a complete fermentation and exhibit a fermentative phenotype with the advantages of both species but with no collateral effects. These hybrids could be very successful in the dried yeast market for warm viticultural areas. Figure 4 shows a microscopic observation of a mixed fermentation by L. thermotolerans and S. pombe.

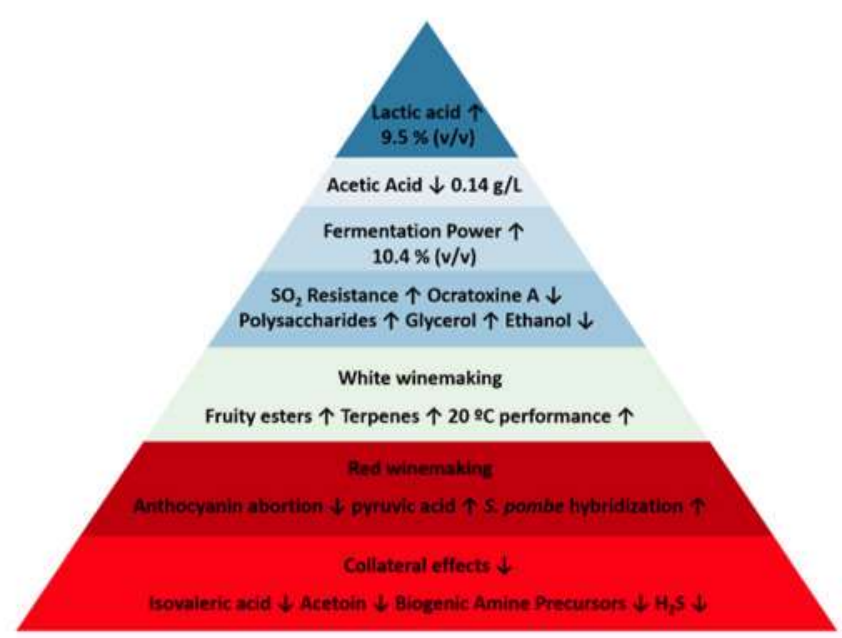

Fig. 4 Summary of proposed Lachancea thermotolerans selection parameters 


\section{L. thermotolerans compared to other non-Saccharomyces} species

During recent years, different scientific studies have reported the performance of several non-Saccharomyces yeasts in winemaking (Jolly et al. 2014). Most of these yeasts have been shown to possess some advantages under specific scenarios (Varela et al. 2016), making it difficult for winemakers to decide which is the most appropriate yeast for their specific case. Comparative studies have shown that $L$. thermotolerans produces greater amounts of lactic acid than any other nonSaccharomyces species. However, other interesting parameters have also shown significant differences.

In a comparative study with three non-Saccharomyces sequential fermentations compared to an $S$. cerevisiae control (Benito et al. 2015a), L. thermotolerans showed no differences from $M$. pulcherrima and $P$. kluyveri in acetic acid production, final ethanol concentration, glycerol, methanol, and free sulfur dioxide. However, fermentations with $P$. kluyveri showed higher final values in residual sugars, glycerol, and methanol than those from $M$. pulcherrima. In a study using pure cultures, Esccribano et al. (2018) observed no statistically significant differences in the residual sugars from $L$. thermotolerans pure fermentations compared to those from $T$. delbrueckii, and $Z$. bailii fermentations that varied from 47 to $96 \mathrm{~g} / \mathrm{L}$. Despite this, fermentations by $M$. pulcherrima, $C$. zeylanoides, and $D$. hansenii showed higher levels, varying from 111 to $201 \mathrm{~g} / \mathrm{L}$. L. thermotolerans produced greater amounts of glycerol than D. hansenii, C. zeylanoides, and $T$. delbrueckii, varying from 4 to $0.6 \mathrm{~g} / \mathrm{L}$, while $M$. pulcherrima showed similar levels, and Z. bailii showed the highest levels, up to $0.95 \mathrm{~g} / \mathrm{L}$. L. thermotolerans showed lower levels of acetic acid than C. zeylanoides by approximately $0.15 \mathrm{~g} / \mathrm{L}$, similar to those of $T$. delbrueckii and Z. bailli, but higher than those of $M$. pulcherrima and $D$. hansenii that varied from 0.05 to $0.1 \mathrm{~g} / \mathrm{L}$. L. thermotolerans, in sequential fermentations with $S$. cerevisiae, showed lower final concentrations of fructose than those obtained in an $S$. pombe pure culture fermentation (Chen et al. 2018). In the same study, T. delbrueckii sequential fermentations showed lower final concentrations of acetic acid $(0.1 \mathrm{~g} / \mathrm{L})$, while one selected $S$. pombe strain produced similar acetic acid concentrations and an unselected one had higher values up to $0.6 \mathrm{~g} / \mathrm{L}$. Z bailii produced significant amounts of sulfur dioxide that were $19 \mathrm{mg} / \mathrm{L}$ higher than the $L$. thermotolerans fermentation (Escribano et al. 2018). Malic acid degradation was similar to those of $D$. hansenii, $M$. pulcherrima, and $T$. delbrueckii, but higher than that of $C$. zeylanoides and Z. bailii, varying from 0.2 to $0.5 \mathrm{~g} / \mathrm{L}$ (Escribano et al. 2018).

Slightly higher concentrations are reported for the concentrations of the total acetaldehydes $(4 \mathrm{mg} / \mathrm{L})$ and pyruvic acid (10 mg/L) of $L$. thermotolerans compared to fermentations involving $M$. pulcherrima and P. kluyveri (Benito et al. 2015a). Other studies report that $S$. pombe produces higher concentrations of acetaldehyde and pyruvic acid that are approximately 30 and $100 \%$ greater than those of $L$. thermotolerans (Benito et al. 2017; Chen et al. 2018). L. thermotolerans produced similar levels of acetaldehyde compared to those of $M$. pulcherrima, T. delbrueckii, and Z. bailii, and lower levels than that of $C$. zeylanoides by approximately $28 \mathrm{mg} / \mathrm{L}$, and higher levels than that of $D$. hansenii that did not produce any acetaldehyde (Esccribano et al. 2018). L. thermotolerans produced levels of pyruvic acid similar to those of $D$. hansenii and $M$. pulcherrima, but lower than those of $T$. delbrueckii, C. zeylanoides, and $Z$. bailii at 22, 54, $140 \mathrm{mg} / \mathrm{L}$, respectively. L. thermotolerans produced levels of succinic acid similar to those of $C$. zeylanoides, $T$. delbrueckii, and $M$. pulcherrima, but much higher than that of $D$. hansenii by approximately $320 \mathrm{mg} / \mathrm{L}$, and much lower than that of $Z$. bailii by approximately $300 \mathrm{mg} / \mathrm{L}$ (Escribano et al. 2018).

L. thermotolerans fermentations showed a greater production of higher alcohols than $M$. pulcherrima by approximately $20 \mathrm{mg} / \mathrm{L}$, while no differences were observed for $P$. kluyveri (Benito et al. 2015a). In another study, L. thermotolerans produced final concentrations of higher alcohols similar to those of T. delbrueckii, M. pulcherrima, and Z. bailii, but lower than those of $D$. hansenii and $C$. zeylanoides (Escribano et al. 2018). L. thermotolerans produced higher total ethyl esters than $M$. pulcherrima and $P$. kluyveri by approximately $5 \mathrm{mg}$ L. $M$. pulcherrima sequential fermentations produced fewer acetate esters by approximately $10 \mathrm{mg} / \mathrm{L}$, while no differences were observed for P. Kluyveri (Benito et al. 2015a). In another study, $L$. thermotolerans produced levels of ethyl esters similar to those of $T$. delbrueckii and $M$. pulcherrima, but higher than that of $Z$. bailii by $0.16 \mathrm{mg} / \mathrm{L}$ or those of $D$. hansenii and C. zeylanoides that did not produce significant amounts (Escribano et al. 2018). L. thermotolerans consistently produces higher levels of ethyl lactate than any other nonSaccharomyces yeast due to its increased levels of lactic acid production (Benito et al. 2016b; Chen et al. 2018; Escribano et al. 2018). L. thermotolerans fermentations resulted in lower levels of total fatty acids (by $\sim 2 \mathrm{mg} / \mathrm{L}$ ) than those of $M$. pulcherrima and P. kluyveri (Benito et al. 2015a). The largest differences were observed in the total terpenes, in which $L$. thermotolerans sequential fermentations showed significant differences, up to $90 \mu \mathrm{g} / \mathrm{L}$, compared to the other nonSaccharomyces fermentations. T. delbrueckii and Z. bailii produced higher levels of methanol than $L$. thermotolerans at 5 and $3 \mathrm{mg} / \mathrm{L}$, respectively (Escribano et al. 2018). L. thermotolerans produced higher levels of acetoin than $T$. delbrueckii, but lower levels than $C$. zeylanoides and $M$. pulcherrima (Escribano et al. 2018).

$L$. thermotolerans showed a total polyphenol index similar to those of $M$. pulcherrima and T. delbrueckii, but lower than that observed for S. pombe fermentations (Chen et al. 2018). $L$. 
thermotolerans showed a gelatin index similar to the other studied non-Saccharomyces yeasts, except for $M$. pulcherrima that produced lower levels of approximately $50 \%$. The $\mathrm{HCl}$ and vanillin indices were also higher solely for the $S$. pombe species.

L. thermotolerans showed higher levels of grape anthocyanin concentrations (i.e., delphinidin, cyanidin, petunidin, and peonidin) than those of $T$. delbrueckii and $M$. pulcherrima (Chen et al. 2018). In the case of malvidin, this effect did not occur for $T$. delbrueckii, but it was observed for $M$. pulcherrima and S. pombe. Vitisin levels were similar to those of $T$. delbrueckii and M. pulcherrima, but lower than that of $S$. pombe. L. thermotolerans produced fewer acetaldehydes than $S$. pombe produced in its fermentations. Sequential fermentations involving $L$. thermotolerans and $S$. cerevisiae produced higher final concentrations of non-acetylated anthocyanins than equivalent sequential fermentations by $M$. pulcherrima and $T$. delbrueckii at approximately 6 and $11 \mathrm{mg} / \mathrm{L}$ (Escott et al. 2018). M. pulcherrima fermentations showed higher levels of vitisins at approximately $0.01 \mathrm{mg} / \mathrm{L}$, while the $L$. thermotolerans sequential fermentations did not show any vinylphenolic pyranoanthocyanin formation, and $M$. pulcherrima and $T$. delbrueckii showed higher levels up to $0.1 \mathrm{mg} / \mathrm{L}$. L. thermotolerans showed total pigment concentrations higher than those of M. pulcherrima and T. delbrueckii at approximately 8 and $13 \mathrm{mg} / \mathrm{L}$.

In a study comparing polysaccharide releases by eight nonSaccharomyces yeasts in sequential inoculations against a $S$. cerevisiae control, only P. fermentans, S. ludwigii, and $T$. delbrueckii performed better (Domizio et al. 2014). S. ludwigii showed an increase of $50 \%$, while the polysaccharide increases for $P$. fermentans and $T$. delbrueckii were approximately $25 \%$. Other research that indirectly studied the polysaccharide release through the study of the ethanol index (Chen et al. 2018) observed similar values between the species M. pulcherrima, T. delbrueckii, and L. thermotolerans. S. pombe showed values up to 3 to 4 times higher, most likely due to the higher polysaccharide release from that species. Table 4 summarizes the primary fermentation parameters compared to $L$. thermotolerans and the other nonSaccharomyces species in winemaking.

\section{Future specific selection criteria for $L$. thermotolerans strains}

Although the primary enological use of $L$. thermotolerans is to increase the acidity of wines through the production of lactic acid, there are large variations in lactic acid formation depending on the strain studied. Esribano et al. 2018 reports a $3.3 \mathrm{~g} / \mathrm{L}$ variability from 0.9 to $4.2 \mathrm{~g} / \mathrm{L}$ in a study that compared four different strains. Therefore, it is critical to establish lactic acid production as the main criterion in $L$. thermotolerans selection, since some strains could not achieve the desired objective during industrial conditions. The highest lactic acid formation reported was $9.6 \mathrm{~g} / \mathrm{L}$ (Kapsopoulou et al. 2005), which could establish the desired level for this selection process. The second criterion should be the lowest production of volatile acidity, since approximately $50 \%$ variability in strains have been reported by several authors (Comitini et al. 2011; Escribano et al. 2018). Values close to the lowest reported concentration of $0.14 \mathrm{~g} / \mathrm{L}$ (Escribano et al. 2018) can help to establish this criterion. Although with most $L$. thermotolerans applications in winemaking, the alcoholic fermentation is properly finished by another more fermentative yeast species, such as $S$. cerevisiae or S. pombe (Benito et al. 2018); the fermentation power must also be considered for strain selection, because increased fermentation rates will help to produce the acidification desired (Kapsopoulou et al. 2007; Comitini et al. 2011). The reported strain variability is $\sim 3.98 \%(v / v)$ (Comitini et al. 2011), with maximal reported values for a pure culture at $~$ $10.46 \%(v / v)$ (Gobbi et al. 2013). This criterion would also allow for applications using $L$. thermotolerans as a pure culture in other fermentation industries that produce beverages with lower final ethanol contents (i.e., beer, sweet wines, or sparkling base wines). Several studies and commercial producers have described $L$. thermotolerans as having a lower tolerance to $\mathrm{SO}_{2}$; however, one study reported that four of the five strains studied could not withstand $\mathrm{SO}_{2}$ concentrations greater than $20 \mathrm{mg} / \mathrm{L}$, but a single strain was tolerant to $\mathrm{SO}_{2}$ concentrations between 20 and $40 \mathrm{mg} / \mathrm{L}$ (Comitini et al. 2011). The selection of strains highly resistant to $\mathrm{SO}_{2}$ action would increase the use of $L$. thermotolerans on an industrial scale, since the use of this yeast is typically reserved for very healthy grapes where high doses of $\mathrm{SO}_{2}$ are not needed.

Among some of the possible undesirable volatile compounds, some studies have reported a tendency for $L$. thermotolerans to produce higher levels of isovaleric acid and acetoin; however, this appears to be strain-dependent behavior (Escribano et al. 2018). Since variability in the production of these two compounds among the studied strains was 55 and $95 \%$, respectively, the selection of $L$. thermotolerans strains producing those compounds below the detection thresholds is critical. The production of $\mathrm{H}_{2} \mathrm{~S}$ has been reported with a variability of $40 \%$ among strains (Comitini et al. 2011) and should also be considered to avoid undesirable reductive aromas in wines. Fermentation by $L$. thermotolerans at temperatures lower than conventional protocols $\left(20^{\circ} \mathrm{C}\right)$, where greater quantities of aromatic compounds accumulate, could constitute an interesting secondary criterion for increasing the quality of some parameters (Gobbi et al. 2013).

Some authors have reported increases in the release of polysaccharides during $L$. thermotolerans fermentations compared to the $S$. cerevisiae control (Comitini et al. 2011), with strain variability for this parameter at up to $60 \%$ (Gobbi et al. 2013). Some modern enologists are demanding sensory characteristics related to these compounds. Therefore, polysaccharide concentrations should also be considered. 
Comparison of $L$. thermotolerans to other non-Saccharomyces yeasts for some oenology parameters

$\begin{array}{llllllllll}\text { L. } & P & S & T & M & P & Z & C & D . & S . \\ \text { thermotolerans } & \text { fermentans } & \text { ludwigi } & \text { delbruechii } & \text { pulcherrima } & \text { khuveri } & \text { baihi } & \text { zevlanoides } & \text { hansenii } & \text { pombe }\end{array}$

\begin{tabular}{|c|c|c|c|c|c|c|c|c|c|c|}
\hline Lactic acid & $\uparrow \uparrow$ & & & & & & & & & \\
\hline Acetic acid & & & & $\approx 1 \downarrow$ & $\approx$ & $\approx$ & $\uparrow$ & $\uparrow$ & & $\approx / \uparrow$ \\
\hline Glycerol & & & & $\downarrow$ & $\approx$ & $\approx$ & $\uparrow$ & $\downarrow$ & $\downarrow$ & \\
\hline Methanol & & & & $\uparrow$ & $\approx$ & $\approx$ & $\uparrow$ & & & \\
\hline Free $\mathrm{SO}_{2}$ & & & & & $\approx$ & $\approx$ & & & $\uparrow$ & \\
\hline Acetaldehyde & & & & $\approx$ & $\downarrow$ & $\downarrow$ & $\approx$ & $\downarrow$ & $\downarrow$ & $\uparrow$ \\
\hline Pyruvic acid & & & & $\uparrow$ & $\downarrow$ & $\downarrow$ & $\uparrow$ & $\uparrow$ & $\approx$ & $\uparrow$ \\
\hline Ethyl esters & $\uparrow$ & & & & $\downarrow$ & $\downarrow$ & $\downarrow$ & $\downarrow$ & $\downarrow$ & \\
\hline Acetate esters & & & & $\approx$ & $1 / \approx$ & $\approx$ & $\approx$ & $\downarrow$ & $\downarrow$ & \\
\hline Higher alcohols & $\uparrow$ & & & & $\downarrow$ & $\approx$ & & & & \\
\hline Fatty acids & $\downarrow$ & & & & $\uparrow$ & $\uparrow$ & & & & \\
\hline Terpenes & $\uparrow$ & & & & $\downarrow$ & $\downarrow$ & & & & \\
\hline Alcohol production & & & $\approx$ & $\approx$ & & & $\approx$ & & & $\uparrow$ \\
\hline $\begin{array}{l}\text { Malic acid } \\
\text { degradation }\end{array}$ & & & & $\approx$ & $\approx$ & & $\downarrow$ & $\downarrow$ & $\approx$ & $\uparrow \uparrow$ \\
\hline Succinic acid & & & & $\approx$ & $\approx$ & & $\uparrow$ & $\approx$ & $\downarrow$ & \\
\hline Ethyl lactate & $\uparrow \uparrow$ & & & & & & & & & \\
\hline Acetoin & & & & $\downarrow$ & $\uparrow$ & & & $\uparrow$ & & \\
\hline $\begin{array}{l}\text { Anthocyanin } \\
\text { absorption }\end{array}$ & $\downarrow$ & & $\uparrow$ & $\uparrow$ & & & & & & $\uparrow$ \\
\hline Polysaccharides & & $\uparrow$ & $\uparrow$ & $\uparrow$ & $\downarrow$ & & & & & $\uparrow \uparrow$ \\
\hline
\end{tabular}

$\uparrow:$ higher activity. $\downarrow$ : lower activity, $\approx$ similar activity

Since specific $L$. thermotolerans strains can reduce food safety concerns about compounds such as OTA (Ponsone et al. 2016), increased research is required to generate products to ferment grape harvests with rot, in which OTA levels can exceed the legal limits. Although there is no direct correlation between the presence of biogenic amine precursors and the final concentrations of biogenic amines. some authors have reported that $L$. thermotolerans tends to release greater amounts of lysine, ornithine, and tyrosine than the $S$. cerevisiae controls (Benito et al., 2015a, b; Benito et al., $2016 \mathrm{a}, \mathrm{b}, \mathrm{c})$. It would be prident for researchers to select $L$. thermotolerans strains with decreased abilities to release those biogenic amine precursors.

Due to the great variability in pyruvic acid production among $L$. thermotolerans strains $(30 \%)$ (Escribano et al. 2018), specific strains could be selected to increase the formation of highly stable color forms. such as vitisin A (Benito et al. 2018a), or to decrease the production of ethanol levels, since the glycerol-pyruvic acid pathway is associated with the production of wines with lower final ethanol concentrations (Belda et al. 2015). A similar effect was observed for succinic acid (35\% variability) (Escribano et al. 2018). Figure 4 summarizes the main parameters proposed for future selections of $L$. thermotolerans strains.

\section{Conclusion}

L. thermotolerans has been investigated to improve wine quality, as described in the scientific literature, primarily due to its ability to increase acidity through the generation of lactic acid. That ability is an important resource for warm viticultural regions that produce grapes with a lack of acidity, in addition to other regions that will face this problem in the future due to climate change. In addition, the scientific literature reports that $L$. ihennotolerans can improve other fermentation parameters that affect wine quality and positively influence sensory perception. such as the production of increases in the positive aroma compounds (i.e.. terpenes and isobutyrate); a reduction in acetic acid and acetaldehyde concentrations. and increases in glycerol. pyruvic acid, grape anthocyanins. and polysaccharides. The applications for improving food safety, such as the reduction of ochratoxin A (OTA) and biogenic amines, also appear to be highly promising.

While there are many advantages to using $L$. thermotolerans in winemaking. several authors have also reported some serious disadvantages, such as the lack of fermentation power or increases in undesirable molecules (e.g., isovaleric acid, succinic acid, or acetoin) under some circumstances. However, these collateral effects appear to be strain dependent, as do most of the desired advantages. Therefore, 
future selection processes for increasing market-available strains should begin immediately.

Funding Funding for the research in this paper was provided by Ossian Vides y Vinos S.L, under the framework of the project FPA1720300120 (Centre for Industrial Technological Development-CDTI, Spain).

\section{Compliance with ethical standards}

This article does not contain any studies with human participants or animals performed by any of the authors.

Conflicts of interest The author declares that he has no conflict of interest.

\section{References}

Balikci EK, Tanguler H, Jolly NP, Erten H (2016) Influence of Lachancea thermotoleranson cv. Emir wine fermentation. Yeast 33:313-321. https://doi.org/10.1002/yea.3166

Banilas G, Sgouros G, Nisiotou A (2016) Development of microsatellite markers for Lachancea thermotolerans typing and population structure of wine-associated isolates. Microbiol Res 193:1-10. https:// doi.org/10.1016/j.micres.2016.08.010

Belda I, Navascués E, Marquina D, Santos A, Calderon F, Benito S (2015) Dynamic analysis of physiological properties of Torulaspora delbrueckii in wine fermentations and its incidence on wine quality. Appl Microbiol Biotechnol 99:1911-1922. https://doi.org/10.1007/s00253-014-6197-2

Belda I, Navascués E, Marquina D, Santos A, Calderón F, Benito S (2016) Outlining the influence of non-conventional yeasts in wine ageing over lees. Yeast 33:329-338. https://doi.org/10.1002/yea. 3165

Belda I, Ruiz J, Beisert B, Navascués E, Marquina D, Calderón F, Rauhut D, Benito S, Santos A (2017) Influence of Torulaspora delbrueckii in varietal thiol (3-SH and 4-MSP) release in wine sequential fermentations. Int J Food Microbiol 257:183-191. https://doi.org/10. 1016/j.jifoodmicro.2017.06.028

Benito S, Hofmann T, Laier M, Lochbühler B, Schüttler A, Ebert K, Fritsch S, Röcker J, Rauhut D (2015a) Effect on quality and composition of Riesling wines fermented by sequential inoculation with non-Saccharomyces and Saccharomyces cerevisiae. Eur Food Res Technol 241:707-717. https://doi.org/10.1007/s00217-015-2497-8

Benito Á, Calderón F, Palomero F, Benito S (2015b) Combine use of selected Schizosaccharomyces pombe and Lachancea thermotolerans yeast strains as an alternative to the traditional malolactic fermentation in red wine production. Molecules 20:9510 9523. https://doi.org/10.3390/molecules20069510

Benito Á, Jeffares D, Palomero F, Calderón F, Bai F-Y, Bähler J, Benito S (2016a) Selected Schizosaccharomyces pombe strains have characteristics that are beneficial for winemaking. PLoS One 11:e0151102. https://doi.org/10.1371/journal.pone.0151102

Benito Á, Calderón F, Palomero F, Benito S (2016b) Quality and composition of Airen wines fermented by sequential inoculation of Lachancea thermotolerans and Saccharomyces cerevisiae. Food Technol Biotechnol 54:135-144. https://oi.org/10.17113/ftb.54. 02.16 .4220

Benito Á, Calderón F, Benito S (2016c) Combined use of $S$. pombe and $L$. thermotolerans in winemaking. Beneficial effects determined through the study of wines' analytical characteristics. Molecules 21:1744. https://doi.org/10.3390/molecules 21121744
Benito A, Calderon F, Benito S (2017) The combined use of Schizosaccharomyces pombe and Lachancea thermotolerans-effect on the anthocyanin wine composition. Molecules 22:739. https:// doi.org/ $10.3390 /$ molecules 22050739

Benito A, Calderon F, Benito S (2018a) Schizosaccharomyces pombe biotechnological applications in winemaking. In: Singleton TL (ed) Methods molecular biology. Springer, Berlin, Germany, Chapter 20. ISBN 978-1-4939-7545-7 365-370

Benito A, Calderon F, Benito S (2018b) Schizosaccharomyces pombe Isolation Protocol. In: Singleton TL (ed) Methods molecular biology. Springer, Berlin, Germany, Chapter 20. ISBN 978-1-4939-7545$7365-370$

Bonciani T, Solieri L, De Vero L, Giudici P (2016) Improved wine yeasts by direct mating and selection under stressful fermentative conditions. Eur Food Res Technol 242:899 910. https://doi.org/10.1007/ s00217-015-2596-6

Canonico L, Agarbati A, Comitini F, Ciani M (2016) Torulaspora delbrueckii in the brewing process: a new approach to enhance bioflavour and to reduce ethanol content. Food Microbiol 56:4551. https://doi.org/10.1016/j.fm.2015.12.005

Canonico L, Comitini F, Ciani M (2017) Torulaspora delbrueckï contribution in mixed brewing fermentations with different Saccharomyces cerevisiae strains. Int J Food Microbiol 259:7-13. https://doi.org/10.1016/j.ijfoodmicro.2017.07.017

Chen K, Escott C, Loira I, del Fresno JM, Morata A, Tesfaye W, Calderon F, Suárez-Lepe JA, Han S, Benito S (2018) Use of nonSaccharomyces yeasts and oenological tannin in red winemaking: influence on colour, aroma and sensorial properties of young wines. Food Microbiol 69:51-63. https://doi.org/10.1016/j.fm.2017.07.018

Ciani M, Beco L, Comitini F (2006) Fermentation behaviour and metabolic interactions of multistarter wine yeast fermentations. Int J Food Microbiol 108:239-245. https://doi.org/10.1016/j.ijfoodmicro. 2005.11 .012

Ciani M, Morales P, Comitini F, Tronchoni J, Canonico L, Curiel JA, Oro L, Rodrigues AJ, Gonzalez R (2016) Non-conventional yeast species for lowering ethanol content of wines. Front Microbiol 7:642. https:/doi.org/10.3389/fmicb.2016.00642

Comitini F, Gobbi M, Domizio P, Romani C, Lencioni L, Mannazzu I, Ciani M (2011) Selected non-Saccharomyces wine yeasts in controlled multistarter fermentations with Saccharomyces cerevisiae. Food Microbiol 28:873-882. https://doi.org/10.1016/j.fm.2010.12.001

Contreras A, Hidalgo C, Henschke PA, Chambers PJ, Curtin C, Varela C (2014) Evaluation of non-Saccharomyces yeasts for the reduction of alcohol content in wine. Appl Environ Microbiol 80:1670-1678. https://doi.org/10.1128/aem.03780-13

Deák T (2008) Handbook of food spoilage yeasts, 2nd edn. CRC Press, Boca Raton

Domizio P, Liu Y, Bisson LF, Barile D (2014) Use of non-Saccharomyces wine yeasts as novel sources of mannoproteins in wine. Food Microbiol 43:5-15. https://doi.org/10.1016/j.fm.2014.04.005

Domizio P, House JF, Joseph CML, Bisson LF, Bamforth CW (2016) Lachancea thermotolerans as an alternative yeast for the production of beer. J Inst Brew 122:599-604, https://doi.org/10.1002/jib.362

Domizio P, Liu Y, Bisson LF, Barile D (2017) Cell wall polysaccharides released during the alcoholic fermentation by Schizosaccharomyces pombe and S. japonicus: quantification and characterization. Food Microbiol 61:136-149. https://doi.org/10.1016/j.fm.2016.08.010

Du Plessis H, Du Toit M, Hoff J, Hart R, Ndimba B, Jolly N (2017) Characterisation of non-Saccharomyces yeasts using different methodologies and evaluation of their compatibility with malolactic fermentation. South Afr J Enol Vitic 38:46-63. https://doi.org/10. 21548/38-1-819

Escott C, Del Fresno JM, Loira I, Morata A, Tesfaye W, del Carmen GM, Suárez-Lepe JA (2018) Formation of polymeric pigments in red wines through sequential fermentation of flavanol-enriched musts 
with non-Saccharomyces yeasts. Food Chem 239:975-983. https:// doi.org/10.1016/j.foodchem.2017.07.037

Escribano R, González-Arenzana L, Portu J, Garijo P, López-Alfaro I, López R, Santamaría P, Gutiérrez AR (2018) Aromatic compound production and fermentative behavior within different nonSacchanomyces species and clones. J Appl Microbiol 124:15211531. https://oi.org/10.1111/jam. 13735

European Commission (2006) Commision Regulation (EC) N 1881/2006 of 19 December 2006 setting maximum levels for certain contaminants in foodstuffs. Off J Eur Union 364:5-24

Fell JW, Statzell-Tallman A, Kurtzman CP (2004) Lachancea meyersii sp. nov., an ascosporogenous yeast from mangrove regions in the Bahama Islands. Stud Mycol 50:359-363

Gobbi M, Comitini F, Domizio P, Romani C, Lencioni L, Mannazzu I, Ciani M (2013) Lachancea thermotolerans and Saccharomyces cerevisiae in simultaneous and sequential co-fermentation: a strategy to enhance acidity and improve the overall quality of wine. Food Microbiol 33:271-281. https:/doi.org/10.1016/j.fm.2012.10.004

Gonzalez-Ramos D, Cebollero E, Gonzalez R (2008) A recombinant Saccharomyces cerevisiae strain overproducing mannoproteins stabilizes wine against protein haze. Appl Environ Microbiol 74:5533 5540. https://doi.org/10.1128/AEM.00302-08

González-Royo E, Pascual O, Kontoudakis N, Esteruelas M, EsteveZarzoso B, Mas A, Canals JM, Zamora F (2015) Oenological consequences of sequential inoculation with non-Saccharomyces yeasts (Torulaspora delbrueckii or Metschnikowia pulcherrima) and Saccharomyces cerevisiae in base wine for sparkling wine production. Eur Food Res Technol 240:999-1012. https://doi.org/10.1007/ s00217-014-2404-8

Hranilovic A, Bely M, Masneuf-Pomarede I, Jiranek V, Albertin W (2017a) The evolution of Lachancea thermotolerans is driven by geographical determination, anthropisation and flux between different ecosystems. PLoS One 12:e0184652. https://doi.org/10.1371/ journal.pone. 0184652

Hranilovic A, Li S, Boss PK, Bindon K, Ristic R, Grbin PR, Van der Westhuizen T, Jiranek V (2017b) Chemical and sensory profiling of Shiraz wines co-fermented with commercial non-Saccharomyces inocula. Aust J Grape Wine Res 24:166-180. https://doi.org/10. 1111/ajgw.12320

International Agency for Research on Cancer (IARC) (1993) Ochratoxin A. Monographs on the evaluation of carcinogenic risks to humans: some naturally occurring substances, food items and constituents, heterocyclic aromatic amines and mycotoxines. IARC Monogr Eval Carcinog Risks Hum 56:489-521

Jolly NP, Augustyn OPH, Pretorius IS (2003) The effect of nonSaccharomyces yeasts on fermentation and wine quality. South Afr J Enol Vitic 24:55-62. https://doi.org/10.21548/24-2-2638

Jolly NP, Varela C, Pretorius IS (2014) Not your ordinary yeast: nonSaccharomyces yeasts in wine production uncovered. FEMS Yeast Res 14:215-237. https://doi.org/10.1111/1567-1364.12111

Kapsopoulou K, Kapaklis A, Spyropoulos H (2005) Growth and fermentation characteristics of a strain of the wine yeast Kluyveromyces thermotolerans isolated in Greece. World J Microbiol Biotechnol 21:1599-1602. https://doi.org/10.1007/s11274-005-8220-3

Kapsopoulou K, Mourtzini A, Anthoulas M, Nerantzis E (2007) Biological acidification during grape must fermentation using mixed cultures of Kluyveromyces thermotolerans and Saccharomyces cerevisiae. World J Microbiol Biotechnol 23:735-739. https://doi. org/10.1007/s11274-006-9283-5

Kurtzman CP (2003) Phylogenetic circumscription of Saccharomyces, Kluyveromyces and other members of the Saccharomycetaceae, and the proposal of the new genera Lachancea, Nakaseomyces,
Naumovia, Vanderwaltozyma and Zygotorulaspora. FEMS Yeast Res 4:233-245. https://oi.org/10.1016/S1567-1356(03)00175-2

Kurtzman CP, Robnett CJ (2003) Phylogenetic relationships among yeasts of the 'Saccharomyces complex'determined from multigene sequence analyses. FEMS Yeast Res 3:417-432. https://doi.org/10. 1016/S1567-1356(03)00012-6

Lachance MA, Kurtzman CP (2011) Lachancea Kurtzman (2003). In: Kurtzman C, Fell JW, Boekhout T (eds) The yeasts: a taxonomic study, 5th edn. Elsevier, Amsterdam, pp 511-519

Malpertuy A, Llorente B, Blandin G, Artiguenave F, Wincker P, Dujon B (2000) Genomic exploration of the hemiascomycetous yeasts: 10. Khyveromyces thermotolerans. FEBS Lett 487:61-65. https://doi. org/10.1016/S0014-5793(00)02281-X

Michel M, Kopecká J, Meier-Dörnberg T, Zarnkow M, Jacob F, Hutzler M (2016) Screening for new brewing yeasts in the nonSaccharomyces sector with Torulaspora delbrueckii as model. Yeast 33:129-144. https://doi.org/10.1002/yea.3146

Mylona AE, Del Fresno JM, Palomero F, Loira I, Bañuelos MA, Morata A, Calderón F, Benito S, Suárez-Lepe JA (2016) Use of Schizosaccharomyces strains for wine fermentation - effect on the wine composition and food safety. Int J Food Microbiol 232:63-72. https://oi.org/10.1016/j.ijfoodmicro.2016.05.023

Padilla B, Gil JV, Manzanares P (2016) Past and future of nonSaccharomyces yeasts: from spoilage microorganisms to biotechnological tools for improving wine aroma complexity. Front Microbiol 7:411. https:/doi.org/10.3389/fmicb.2016.00411

Petruzzi L, Capozzi V, Berbegal C, Corbo MR, Bevilacqua A, Spano G, Sinigaglia M (2017) Microbial resources and enological significance: opportunities and benefits. Front Microbiol 8:995. https:// doi.org/10.3389/fmicb.2017.00995

Ponsone ML, Chiotta ML, Combina M, Dalcero A, Chulze S (2011) Biocontrol as a strategy to reduce the impact of ochratoxin a and Aspergillus section Nigri in grapes. Int J Food Microbiol 151:70-77 https://doi.org/10.1016/j.ijfoodmicro.2011.08.005

Ponsone ML, Nally MC, Chiotta ML, Combina M, Köhl J, Chulze SN (2016) Evaluation of the effectiveness of potential biocontrol yeasts against black sur rot and ochratoxin A occurring under greenhouse and field grape production conditions. Biol Control 103:78-85. https://doi.org/10.1016/j.biocontrol.2016.07.012

Schwan RF, Wheals AE (2003) Mixed microbial fermentations of chocolate and coffee. In: Boekhout T, Robert V (eds) Yeasts in food. Beneficial and Detrimental Aspects B. Behr's Verlag, Hamburg, pp 429-449

Senses-Ergul S, Agoston R, Belák A, Deák T (2006) Characterization of some yeasts isolated from foods by traditional and molecular tests. Int J Food Microbiol 108:120-124. https://doi.org/10.1016/j. ijfoodmicro.2005.10.014

Shekhawat K, Porter TJ, Bauer FF, Setati ME (2018) Employing oxygen pulses to modulate Lachancea thermotolerans-Saccharomyces cerevisiae Chardonnay fermentations. Ann Microbiol 68:93-102. https://doi.org/10.1007/s13213-017-1319-6

Varela C (2016) The impact of non-Saccharomyces yeasts in the production of alcoholic beverages. Appl Microbiol Biotechnol 100:98619874. https://doi.org/10.1007/s00253-016-7941-6

Varela C, Sengler F, Solomon M, Curtin C (2016) Volatile flavour profile of reduced alcohol wines fermented with the non-conventional yeast species Metschnikowia pulcherrima and Saccharomyces uvarum. Food Chem 209:57-64. https://doi.org/10.1016/j.foodchem.2016. 04.024

Whitener MEB, Stanstrup J, Carlin S, Divol B, Du Toit M, Vrhovsek U (2017) Effect of non-Saccharomyces yeasts on the volatile chemical profile of Shiraz wine. Aust J Grape Wine Res 23:179-192. https:// doi.org/10.1111/ajgw. 12269 